UDC 613.644: 612.842.5

DOI: $10.21668 /$ health.risk/2016.4.12.eng

\title{
ADAPTATION OF THE MIGRANT WORKER'S BODY TO THE OCCUPATIONAL RISK FACTORS FROM THE POSITION OF FUNCTIONAL SYSTEM OF P.K. ANOKHIN
}

\author{
M. Khodzhiev, L.V. Prokopenko, N.P. Golovkova, G.I.Tikhonova, M.A. Fesenko \\ Research Institute of Occupational Health, 31 Budennov Prospekt, Moscow, 105275, Russian Federation
}

\begin{abstract}
The adverse factors of labor process of migrants were studied as the factors of risk of formation of unsatisfactory adaptation and damage to health. The results of the study of adaptation of migrants to the labor process from the standpoint of the theory of functional systems were presented. The first subsystem of physical activities and neuro-emotional tension of labor determines the formation of certain stages of the adaptation process in terms of heart rate variability (the second subsystem). The result of migrant workers' sympathetic chain of regulation's activity level shows that the adaptive stress syndrome on the physiological indicators is expressed in a change of heart rate variability: different levels of stress index of SI associated with high physical (muscle), neuro-emotional stresses; marked increase in the power of spectrum of very low-frequency component (VLF), while the increase in heart rate. The features of the functional state of the body and the degree of adaptation in terms of activity of regulatory systems - PARS (optimal 1.19 \pm 0.28 ; allowable stress $40.5 \pm 0.62$; overvoltage $6.21 \pm$ 0.82 points) were determined. On the basis of the production studies of migrant workers, the approaches to quantitative evaluation to the degree of adaptation of workers to the labor process associated with the combined effects of physical, neural and emotional labor intensity on the human body were science-based and developed. The degree of stress adaptation process corresponds to the stage of self-control (optimum stress) activation (allowable stress), the mobilization of the 1st, 2nd, 3-th degree (degrees of over-stress of 1,2,3 degrees). Unfavorable stage of mobilization of 2-3 degrees of migrant workers was determined (an increase in the stress index S1, PARS indicator, the relative power of VLF range, a reduction in the SDNN). Events of medical and social support represent the third sub-system in the general system theory.
\end{abstract}

Key words: migrant workers, adaptation, system approach, muscular load, neural and emotional kind of work, healthy lifestyle.

Relevance. Examining adaptive responses which occur in working activities is in most cases re-lated to a necessity to carry out quantitative estimation of physiological costs for works including physical (muscle) and neuro-emotional loads [1]. And as labor physiologists in the previous cen-tury were mostly dealing with issues related to fatigue and over-fatigue, nowadays such prob-lems as stress and overstress become the focus of attention; and issue of a man's adaptation to various environmental conditions is undoubtedly the most important one.

This adaptation issue has occurred due to formation of such social phenomenon as labor migration on the whole territory of the former USSR. Nowadays, labor migration of young people from Central Asia countries is

(C) Khodzhiev M., Prokopenko L.V., Golovkova N.P., Tikhonova G.I., Fesenko M.A., 2016

Makhmadamin Khodzhaev - PhD of Medical Science, senior researcher of laboratory of labor physiology and preventive ergonomics (e-mail: amin.dok@ mail.ru; tel.: +7 (968) 585-12-95).

Lyudmila V. Prokopenko - Doctor of Medical Science, professor, deputy Director for Research (e-mail: prokopenko@ niimt.ru; tel.: +7 (495) 365-46-03).

Nina P. Golovkova - Doctor of Medical Science, Head of laboratory of complex problems Industry of Occupational Medicine (e-mail: niimt@niimt.ru; tel.: +7 (495) 366-44-47).

Galina I. Tikhonova - Doctor of Medical Science, Head. Laboratory of social and health studies (e-mail: gtikhonova@ya.ru; tel.: +7 (495) 366-05-66).

Marina A. Fesenko - Doctor of Medical Science, Head of Laboratory for the prevention of violations of reproductive health of workers (e-mail: reprlab@mail.ru; tel.: +7 (495) 365-29-81). 
widely spread; they come to Russia in order to find work with decent earnings. But migrants' working activity entails impacts exerted on a human body by a whole set of socialpsychological and climate and geographic conditions as well as factors caused by increased labor hardness and neuro-emotional intensity of labor.

Adverse factors of labor hardness are studied by a number of authors as risk factors caus-ing occupational diseases of musculoskeletal system and peripheral nervous system. Probability of occupational disease frequency amounted to not more than $6 \%$ at regional and total loads at optimal 1st category of labor hardness. If labor conditions belonged to the 2nd category (accept-able stress) pathological disorders frequency didn't exceed 17\%. In case of adverse (hard) 3rd category labor occupational diseases occurred in $17.1-28.0 \%$ cases; if labor condition category was 3.2, $28.1-37.0 \%$ cases; if labor condition category is 3.3 occupational diseases may occur in more than $37 \%$ cases [8].

Basing on the results obtained through production and physiological-clinical research we considered the detected values of neuro-emotional labor intensity to be risk factors causing pro-duction-induced pathology evolvement. Clinical research results prove that the higher labor in-tensity category is, the bigger is the share of people with a detected pathology (primary hyper-tension, ischemic heart disease, and neurotic disorders). As per data taken from scientific litera-ture men tend to have greater $\%$ of cardiovascular system pathology, and women, nervous system pathology $[7,8]$.

In most cases, unskilled workers employed at construction sites, road network repairing, and in social sphere suffer from significant stress of adaptation mechanisms even up to depletion of body physiological reserves. Morbidity structure of labor migrants from Tajikistan based on the length of their stay in Russia proves it. Dealing with physical and neuro-emotional labor, mi-grants are exposed to various climate and geographic, social, and neuro-psychological factors which cause diseases evolvement in them.

According to A.P. Berseneva [5] a new approach to health state assessment has been de-veloped: it is based on a degree of a man' s organism adaptation to working conditions and envi-ronment. Here mostly parameters describing regulatory system state and their functional reserve are used as estimation criteria. Degree of regulatory systems stress determines "costs" of a body adaptation to environmental conditions.

Groups of people with different adaptation levels are detected; the first group with satis-factory adaptation to environmental conditions; the second group, with stress of adaptation me-chanisms; the third group, with unsatisfactory adaptation; the fourth group, with adaptation me-chanisms failure. Mass prognostic research technique is mostly based on data concerning cardi-ovascular system state which is considered to be an indicator of a body adaptive responses; this technique is profoundly described in articles and monographs. We used the above-mentioned approach to assessing degree of labor migrants adaptation to factor of labor physical hardness and labor neuro-emotional intensity, as well as social and psychological conditions of environment, and expanded the set of applied research techniques. We assessed neuromuscular system state, applied correlation analysis to reveal correlation between physiological parameters and working process factors and regression analysis to give quantitative grounds for adaptation process stages.

The research goal was to give scientific grounds for physiological and clinical peculiarities which are characteristic for adaptation of migrants from Tajikistan to production, social and psychological and environmental (climatic) conditions of Moscow region; to work our measurements aimed at medical and social support for labor migrants.

If we consider how a man adapts to various production factors and environmental conditions within the framework of system approach developed by P.K. Anokhin [2], we should pay special attention to functional system formation. 
It is system approach that can "help to get an insight into logical correlations between separate facts, and only this approach helps to design new research more successfully and on a higher level" [4]. A search for a system-forming factor is obligatory for system approach. As A.V. Kapustina et al state (2016), it is physical efficiency concept that is of critical importance for system formation in labor physiology as it is related to both labor hardness and neuro-emotional labor intensity as well as to functional state and level of body adaptive responses.

Nowadays, physical efficiency is viewed as amount of body functional possibilities which characterizes a man's capacity to complete maximum amount of work within a specified period of time under intense or long-term stress. Previously, physical efficiency was determined as per technical and economic indices of work, i.e. labor productivity; however, this approach turned out to be insufficient. If we consider labor hardness and labor intensity to be the first subsystem, it becomes evident that impact exerted by adverse factors of increased labor hard-ness and neuro-emotional labor intensity can lead to decrease in physical efficiency as well as changes in functional state of all body systems. Body physiological state and adaptation process level (stage) can be taken as another subsystem in basic system theory. Recovery of resources spent in labor process makes it necessary to correct functional state applying primary prevention activities (procedures to make oneself fit, basic physical training etc.).

Secondary prevention activities (medical examination, regular check-ups) is aimed at preserving high physical efficiency level, preventing occupational and production-induced pathology evolvement. Giving grounds for prevention activities aimed at increasing physical efficiency and optimal development of adaptive responses can be determined as the third subsystem.

Considering physical efficiency of a man as a functional system, V.V. Matyukhin [9] outlines two interrelated subsystems, functional stress and recovery processes. However, it seems justified to outline three subsystems on the contemporary stage of labor physiology de-velopment; they are migrants labor activity in terms of physical (muscle) labor loads parameters and neuroemotional labor intensity loads, functional state as a certain level of adaptation process formation (which often has such stages as self-regulation, activation and mobilization), physiological functions recovery with the use of labor optimization activities and health-improving activities.

Data and methods. Given all the abovementioned, we should consider each subsystem in greater details and describe basic features of a functional system. Physiological research included job analysis as per Guide P2.2.2006-05 [10]; we assessed body functional state as per conventional techniques, such as dynamometry, heart rate definition, systolic pressure measuring, diastolic pressure measuring, physiological changes index (PCI) for circulatory system, heart rate variability, and circulation regulation type (hypo-, hyper- or eukinetic). Psychological testing included defining personal and situational anxiety (Spielberg test) and neurosis level (Eysench technique).

Comparative analysis of adaptation process in labor migrants depending on volumes of physical and neuro-emotional loads

Basing on examination of professional activity type, we formed professional groups of labor migrants depending on degree of their hazard as per labor hardness and intensity parameters. As the obtained data were systematized, we managed to outline several categories of labor activities. Each category of professional activity comprised representatives from occupations with 2 and 3 hazard class and 1, 2 and 3 hazard category in accordance with P 2.2.2006-05. Here students of the first-third year attending Tajik State Medical University and Moscow Mining In-stitute were included into a group with the 2nd (acceptable) class as per labor hardness parame-ters. Workers employed at fruit and vegetable market as well as students sportsmen going in for bullet shooting were estimated as having 3rd class with the 1st labor conditions category. The 3rd class with the 2 nd category included builders-erectors, road network repairmen, female migrants employed in social sphere, and students sportsmen playing volleyball, futsal, as well as doing taekwondo. The 3rd class 
with the 3rd category comprised builderssteelmen, subway builders, fruit and vegetable warehouse workers etc. As we analyzed professional groups distribution as per generalized parameter of labor intensity, we came to a conclusion that the 3rd class with 2-3- category prevailed $(72.7 \%)$, and the 3rd class with the 1 st category had $27.3 \%$. The high level of neuroemotional labor intensity indicates that emotional stress may evolve and it can cause deadaptation and failure of body compensatory mechanisms.

Correlation analysis of labor hardness factors and neuro-emotional labor intensity factors with physiological parameters of neuromuscular and cardiovascular systems enabled distributing them as per rank places. Labor hardness occupied the central place in this system while other factors were distributed as per their rank in the following order: working posture (is authentically related to physiological parameters in $93,3 \%$ cases, $\mathrm{p} \leq 0.05$ ), static load (80.0\%), labor intensity $(73.3 \%)$, emotional load $(66.7 \%)$. Such labor hardness parameters as weight elevated and moved manually and body bendings, followed.

Impact exerted by adverse factors of labor hardness and apparent neuro-emotional labor intensity induces changes in functional state of all body systems, forms peculiarities of adaptive responses, which can be considered the second subsystem in basic system theory. Today there isn't any quantitative definition of stages in sequential transition of adaptive responses from self -regulation to mobilization with various evidence degree; we haven't also found any attempts to detect correlations between stages and physical hardness degree and emotional intensity of labor.

High labor input which is required to detect adaptation processes stress under joint impact exerted by labor hardness factors and labor intensity factors in production conditions made it ne-cessary to give methodical grounds for assessment of labor migrants' adaptation at physical and neuro-emotional labor.

Quantitative assessment technique applied to define body adaptation processes stress as per research results envisages preliminary definition of labor loads nature. First, we determined labor conditions class as per such parameters as physical dynamic load, cargo weight, stereotyped working movements, static load, working posture, body bending, movements in space, for these parameters make up the total estimation of labor process hardness. Second, we assessed labor conditions class as per values of intellectual, sensory, emotional, and monotonous load and working regime which make up labor intensity estimation as per techniques stated in Guide P 2.2.2006-05 [10].

After these two steps were completed we defined value of each parameter in terms of labor conditions class. Conditional coding in \% and points for labor conditions classes revealed that optimal 1st labor conditions class had 6.7 points; acceptable 2nd class, 13.3 points; hazard 3rd class with the 1st category, 20.0 points, hazard 3rd class with the 2nd category, 26.7 points, hazard 3rd class with the 3rd category, 33.3 points. In case of physical labor total score value of each load type was determined as per parameter having the biggest class. In case of neuroemotional labor, assessment of each load type was made in a different way, namely, total score value of each load type was calculated as per formula of score as per patent No. 2546089 issued on February 27, 2015.

The performed analysis of psychophysiologic data taken on labor migrants during a working shift revealed that functional state formation was determined as per level of labor hardness and labor intensity. Builderssteelmen with 3.3 labor hardness class had $25.6 \%$ lower dynamometric parameters of body supporting muscles endurance and $36 \%$ lower maximum muscular performance (MMP) in comparison with baseline; complaints on pain in loin area occurred in $65.3 \%$ cases by the end of the work shift; in thoracic girdle, in $62.3 \%$ cases; in cervical spine, in $58.4 \%$ cases.

Changes in neuromuscular system of builders-erectors having 3.2 labor hardness class in shift dynamics were less apparent. Doing work related to neuro-emotional stress causes more apparent changes in cardiovascular parameters. Research results show that heart rate, systolic pressure, and diastolic 
pressure measuring as per average shift levels gave more information for workers involved in neuro-emotional work than changes in parameters determined by the end of a work shift; such average shift levels measuring can be used to determine adaptive responses stress. We assessed functional state of cardiovascular system in workers from the examined pro-fessional groups basing also on the integral parameter, namely, physiological changes index (PSI) for circulatory system. This index reveals potential capability of a body to adapt to various production loads, i.e. to actual production activity.

The results of examination performed on labor migrants, students and students sportsmen revealed that students who experienced physical loads corresponding to the 2nd acceptable class of labor hardness had low average monthly values of PSI which was the evidence of sufficient functional capabilities of physiological systems and satisfactory adaptation of the examined stu-dents' bodies. Average shift values of PSI detected in builders with labor conditioned assessed as per labor hardness and labor intensity and considered to be the hazard 3rd class with the 2nd and 3rd category indicated that functional capabilities were reduced and a body adaptation to labor load was unsatisfactory.

As degree of adaptation stress grew from self-regulation stage to activation and mobiliza-tion it became apparent in growing share of labor migrants with high level of personal $(42.8 \%)$ and situational $(45.6 \%)$ anxiety and students with increased neurosis level $(42.9 \%)$. Research dedicated to several personality traits seemingly points at probable neurotic disorders evolvement in people with great neuro-emotional labor loads. The obtained results gave us a possibility to justify quantitative assessment of body adaptive responses stress which included calculating reduction in neuromuscular system parameters (\% of a shift from the baseline) and deviations in average shift levels in cardiovascular system parameters, including heart rate variability, from normative and due values (in \%).
We used regression analysis to analyze data on changes in adaptation processes collected on a lot of working people by the end of a working shift as per neuromuscular and cardiovascu-lar system; it allowed us to create a formula to define a level of a body adaptive responses stress. Adaptation process stage is determined as per level of body adaptation stress under influence exerted by labor hardness factors and labor intensity factors at physical and neuro-emotional la-bor. If $\mathrm{Y} \leq$ A, then stage is classified as self-regulation (optimal stress); if $\mathrm{A} \leq \mathrm{Y} \leq \mathrm{B}$, then stage is classified as activation (acceptable stress): if $\mathrm{B} \leq \mathrm{Y} \leq \mathrm{C}$, then stage is classified as I degree mobilization (I degree overstress); if $\mathrm{C} \leq \mathrm{Y} \leq$ $\mathrm{D}$, then stage is classified as II degree mobilization (II degree overstress); if $\mathrm{D} \leq \mathrm{Y}$, then stage is classified as III degree mobilization (III degree overstress).

Physiological changes index (PSI) is one of the parameters of circulatory system adaptation potential. According to R.M. Baevskiy [4], to assess the adaptive capabilities of the organism in the zone of donor and premorbid states, the method of donor control is designed

Prenosologic states are such states in which non-specific components of body adaptive responses and general adaptation syndrome signs prevail. They are usually characterized with functional stress and unsatisfactory adaptation when normal values of basic vital activity parameters are supported at the expense of increased adaptation mechanisms activity, higher tonus of sympa-thetic nervous system in particular. Long-term stress of adaptation mechanisms and increased consumption of body functional resources (high "price" of adaptation to production factors and social and psychological environmental conditions) lead to lower activity of defense and com-pensatory mechanisms. Specific changes in some organs and systems occur; at first they are not predominant, but further on they become leading and we can confirm that pre-morbid state has appeared; this pre-morbid state later transforms into a specific disease. As R.M. Baevskiy points out [4], pre-morbid states as initial diseases stages can remain for a long time (years), and it is during this period when 
basic health-improving activities can be most effective.

As per data given by R.M. Baevskiy [3], strategy of autonomous systems maximum activation takes place on the level of functional reserves mobilization. When their reserves are com-pletely depleted management in a body is provided by central regulation mechanisms. Such management type is characteristic for most nosologic forms. Recovery and rehabilitation processes as well as adaptation to extreme impacts and environmental conditions in labor migrants can be described as gradual transfer from mobilization and activation levels to selfregulation level. As it is shown in works by outstanding labor physiologists, pre-nosologic control is based on determining three components of a body functional state: level of basic physiological systems functioning, their functional reserve, and level of regulatory mechanisms stress.

The level of functioning which is determined as per constant parameters of the most im-portant systems is the least changeable. According to some authors $[4,5,9]$, the level of function-ing is in direct proportion to the degree of regulatory mechanisms stress and is in inverse propor-tion to functional reserves. The higher is the stress degree and the lower is the reserves, the higher is the level of functioning. R.M. Baevskiy [3] developed pre-nosologic control technique based on the level of circulatory system functioning. Circulatory system is known to determine a body's capability to adapt to most adverse factors of working environment. This system plays a most significant role in prenosologic states assessment when specific shifts in other organs and systems haven't occurred yet. Here oxygen-feed function of circulatory system can become a leading limiting factor of adaptation. As we know, any functional system in a body consists of subsystems and the ultimate result depends on proper functioning of each such subsystem [9]. If any of subsystems has lower functioning level, reliability of the whole functional systems de-creases considerably. A great number of correlations as well as their numerous interdependences do not always represent this optimal variant which can secure high operating quality and makes for efficient execution of all working tasks.

As per results of our research we studied correlation dependence between psychophysiological parameters determining successful execution of working tasks by labor migrants. These parameters included cardiovascular system ones (heart rate, blood pressure, PSI). heart rate va-riability parameters (SDNN, SI, PARS, TP, VLF, \%), neuromuscular system parameters (power, muscle endurance of a working right arm, maximum muscle physical efficiency, endurance of body supporting muscles, MMP). Correlation parameters were authentic $(\mathrm{p} \leq 0.05)$ at 0.48 , i.e. critical value $\langle\mathrm{r} »$ amounted to 0.48 . A number of authentic intrasystem correlations amounted to $77.8 \%$ in cardiovascular system and to $66,7 \%$ in neuromuscular system.

We observed smaller quantity $(53.7 \%)$ of intersystem correlations between cardiovascular system and neuro muscular system. When examining correlation dependences we noted oc-currence of additional interrelations between physiological parameters in cardiovascular system. It seems that additional correlations become active to provide cardiovascular system functioning. In other words, the greatest number of correlations was detected as per cardiovascular system parameters and it caused high level of adaptation processes stress and increased physiological costs of work.

The research results prove that there is possibility in principle to use the examined para-meters of heart rate variability as physiological markers showing state of regulatory systems stress in labor migrants under exposure to labor hardness factors and labor intensity factors and in adverse social and psychological environment.

Results of studying adaptation as per heart rate variability parameters in labor mi-grants

Scientific literature analysis showed that in 1996 international recommendations headed "Heart rate variability. Standards of measuring, physiological interpretation and clinical applica-tion" were published. Those recommendations summed up previous 20 years of 
research and ac-cumulated experience. It was recommended to use 4 frequency ranges in spectral analysis of heart rate variability, namely $\mathrm{HF}(0.15-0.45 \mathrm{~Hz})$ showing parasympathetic activity of autonom-ous nervous system, LF $(0.05-0.15 \mathrm{~Hz})$ showing mostly sympathetic branch of baroceptor con-trol. In the authors' opinion, VLF $(0.05-0.005 \mathrm{~Hz})$ had miscellaneous functional significance. Domestic research results as well as results obtained by foreign scientists proved the necessity to correct the recommendations [4]. It was true mostly in respect of VLF range. Results of examin-ing labor migrants revealed that Tadjiks regardless of their sex tended to have authentically $(\mathrm{P}<0.05)$ higher values of VLF spectrum components (in \%) or low waves of the second rank; Russians tended to have higher \% of LF component. Comparative characteristics of HRV spec-tral components was performed in groups of migrants from Tajikistan and native Russians.

Results obtained at examining people aged 18-20 coming from Tajikistan and Moscow region showed that relative contribution of low-frequency spectral waves (VLF\%) in migrants from Tajikistan was higher and amounted to $20 \%$ while their counterparts from Moscow regions had only $15 \%$. Higher values of VLF component were detected in older Tadjiks, $30.73 \pm 3.27 \%$ in women and $30.24 \pm 2.14 \%$ in men against $24.49 \pm 2.92 \%$ and $28.39 \pm 4.11 \%$, correspondingly. And we should note that regardless of sex and region of origin VLF\% grew and HF\% went down as age increased; it coincides with data given by other authors. Nowadays it is thought to be well-proven that HF-component of a spectrum, or respiratory waves, is determined by parasympathet-ic activity whereas LF-component, according to a lot of authors, is related to level of sympathetic system functioning. As for VLF-waves modulation, we can say that their essence is not clear enough and researchers are having heated discussions on the matter. Some authors believe VFL range is closely connected with psycho-emotional stress; VLF can be a good indicator of managing metabolic processes [11-16].
We should note that an integral parameter of regulatory systems activities (PARS) was authentically lower in Russians $(\mathrm{P}<0.05$ in girls and $\mathrm{P}<0.01$ in boys), which was the evidence that Russians were better adapted to extreme climatic and environmental conditions in Russia and had greater functional reserves. $60 \%$ of examined Russians regardless of their sex had op-timal working stress with PARS values equal to 1-3 points. It corresponded to physiological standard or satisfactory adaptation as per functional states classification applied in pre-nosologic diagnostics [4]. At the same time, $70.8 \%$ of labor migrants from Tajikistan who came to Moscow region had functional stress and more apparent regulatory systems stress (PARS was equal to $4-6$ points and more). There were a lot of people with heart rate disorders among them $(14.5 \%$ girls and $26.8 \%$ boys) while there were only $8.3 \%$ girls and $14.8 \%$ boys with the same disorders among Russians.

It can be explained with increase in LFcomponent of heart rate in migrants from Tajikis-tan proving conditioned sympathicotonia occurrence which can later lead to evolvement of dis-eases related to disorders in cardiovascular system regulation. As per data given by S.D. Budaev [6], the results of the performed analysis revealed death cases among migrants who came to work in Lipetsk region of the RF; they also revealed higher level of cardiovascular system morbidity among labor migrants from Tajikistan in comparison with Russians. The same author gives some data on death cases.

The detected peculiarities of HRV parameters (lower general variability, lower values of VLF\% etc.) in native citizens of Moscow can be viewed as the result of long-term adaptation to extreme climatic and environmental conditions of the region which had been lasting for centuries. It can also indicate that labor migrants from Tajikistan have great difficulty with adaptation to these extreme climatic and environmental conditions. A test with fixed respiration rate was used as functional load on cardiorespiratory system in working process. Functional test with fixed respiration rate 
(FRR6, FRR12) is aimed at detecting physiological reserves of cardiovascular activity and body adaptive responses. The research results showed that cardiovascular system response to functional test with fixed respiration rate in Tadjiks migrants was lower in com-parison with Russians living in Moscow region. It also proves there are physiological peculiarities of adaptive responses depending on climatic and geographic conditions of living in highmountain areas of a donor country providing increased ventilation with oxygen and increased myocardial contractility.

The comparative HRV analysis of labor migrants from Tajikistan belonging to basic oc-cupational groups revealed authentic discrepancies as per a lot of parasympathetic activity para-meters between workers depending on class of labor hardness and labor intensity. Heart rate in the groups didn't have any authentic differences while builders, both erectors and subway build-ers, had lower values of parameters characterizing general heart rate variability: (SDNN) was equal to $41.72 \pm 1.86$ and $41.60 \pm 2.01 \mathrm{~ms}$. The obtained data were statistically authentically $(\mathrm{p}<0.05)$ different from SDNN values detected in fruit and vegetable warehouse workers (labor hardness 3.1) and students of 2nd and 3rd year (labor hardness 2 , acceptable), $59.87 \pm 1.55$ and $55.88 \pm$ $1.70 \mathrm{~ms}$, correspondingly.

Parameters characterizing how active parasympathetic section of autonomous nervous system is are authentically higher (SDNN, RMSSD) at $\mathrm{p}<0.001$ and PNN50 $(\mathrm{p}<0.05)$ for 2nd acceptable labor hardness class and 3rd hazard class with1st labor hardness category correspond-ing to activation stage and 1 degree mobilization stage as per conventional adaptation gradation in comparison with $3 \mathrm{rd}$ class with the 2nd and 3rd labor hardness category. Mode amplitude val-ues and stress indices are the evidence that activity of regulation sympathetic section increases as hazard class becomes higher. Here absolute values of these parameters lie within physiological standard range accepted in European authors' research but they are closer to its bottom limit. As a rule, SDNN, RMSSD, PNN50 parameters change in the same direction. Authentic discrepancies in these parameters and in such parameter as MxDMn prove that vegetative balance shifts to pre-valence of sympathetic section of autonomous nervous system on the level of functional reserves mobilization of II and III degree.

Analysis of HRV frequency peculiarities revealed that if labor hardness was 2 nd class and 3.1. class such parameters as total power of spectrum TP $(\mathrm{p}<0.05)$, absolute spectrum power of lower frequency component of variability $(p<0.05)$ characterizing vasomotor center activity were authentically lower.

As per scientific literature, central sections of regulatory systems are known to be represented in cardiointervalogram by waves in VLF range [4]. Indeed, we detected that relative power increased in VLF range waves in builders-erectors and builders-steelmen and in subways builders (labor hardness class 3.23.3) and it indicated higher activity of sympathetic nervous system. We performed correlation analysis of VLF range spectral power and some working process factors. We observed apparent degree of correlation with emotional load $(\mathrm{r}=0.76, \mathrm{p} \leq 0.05)$ and labor intensity $(r=0.65, p \leq 0.05)$. We detected lower degree of correlation with integral labor hardness value $(\mathrm{r}=0.53, \mathrm{p} \leq 0.05)$, and its separate parameters such as static load $(\mathrm{r}=0.50, \mathrm{p} \leq 0.05)$ and working posture $(\mathrm{r}=0.55, \mathrm{p} \leq 0.05)$. A great number of correlations between VLF range and several physiological parameters is quite noticeable; these parameters are heart rate $(r=0.75$, $\mathrm{p} \leq 0.05)$, systolic pressure $(\mathrm{r}=0.75, \mathrm{p} \leq 0.05)$, diastolic pressure $(\mathrm{r}=0.77, \mathrm{p} \leq 0.05)$, endurance of a right working arm ( $\mathrm{r}=0.73, \mathrm{p} \leq 0.05)$, MMP $(r=0.57, p \leq 0.05)$, integral parameter of functional state $(\mathrm{r}=0.61, \mathrm{p} \leq 0.05)$. We determined apparent correlation dependence with PSI $(r=0.84, p \leq 0.05)$, and stress index SI $(r=$ $0.82, \mathrm{p} \leq 0.05)$. As a result we can state that there is a certain interrelation between waves in VLF range and adaptation process.

In R.M. Baevskiy's opinion $[3,4]$ total spectrum power and power in low frequencies range increase at the stage of unstable adaptation and at the activation stage. Activity of 
sympa-thetic nervous system increased at the mobilization stage of II and III degree (labor conditions class 3.2-3.3 as per labor hardness and labor intensity). Power in very low frequencies range also grew up.

Centralization index under joint exposure to labor hardness and labor intensity factors at labor conditions class 3.1 amounts to $3.70 \pm$ 0.91 st.units and grow up to $7.58 \pm 1.11$ and $6.31 \pm 0.95$ st.units at classes 3.2 and 3.3, ccorrespondingly. It indicates that autonomous functions reg-ulation decreases and the role of central regulation mechanisms becomes greater. In other words, as labor hardness and labor intensity grow, abrupt stress of regulatory systems occurs and, con-sequently, regulation reserves fall. Changes become more apparent at 3 rd class with the 3 rd cat-egory. According to centralization index dynamics, we can assume that changes in regulation mechanisms take place and it becomes apparent at 2nd acceptable labor hardness class (students) and hazard 3 rd class with the 1 st category (fruit and vegetable warehouse workers) via relative prevalence of peripheral regulatory centers over central ones; as labor hardness increases, central regulatory mechanisms become more active.

Here mobilization stage is characterized with growing stress index (SI), relative power of VLF\% range, decrease in total spectrum power and time parameters of a cardiointervalogram, SDNN in particular. We observed substantial growth in parameter of regulatory systems activity (PARS), up to $6.0 \pm 0.40$ and $6.21 \pm 0.21$ st. units, which gave the opportunity to define forming functional state. Here adaptation capabilities of a body could be estimated as a state of regulatory systems overstress which was characterized with defense and adaptive mechanisms insufficiency, their inability to provide adequate body response to impacts exerted by working process factors. And here excessive activation of regulatory systems was not supported by relevant functional reserves [3,4].

Migrants' health state as per objective estimate. To make an objective judgment on influence exerted by production and non- production factors causing morbidity frequency for certain diseases, we analyzed their dependence on time spent by migrants at workplaces in the RF (table 1). medical examinations revealed that if work-ing period was shorter than 1 year acute respiratory viral infections (ARVI) (40.8\%) and chronic bronchitis $(38.1 \%)$ prevailed. But as time passed by, migrants adapted to living and working conditions, and by the end of their third year of staying in various Russian regions ARVI and chronic bronchitis morbidity went down. At the same time, as working period grew longer, a number of spinal column diseases also increased and it was a consequence of migrants being employed at hard work (lifting and moving loads, work in a forced working posture etc.).

Gynecological morbidity level in female migrants depended on labor hardness and labor intensity factors. It was shown that if etiological share of contribution made by adverse working process factors into female diseases evolvement amounted to $40-50 \%$ then degree of correlation between diseases and work was average or strong, i.e. a disease was occupationally induced.

Table 1

Prevalence of pathologies in migrants depending on working period (\%)

\begin{tabular}{|l|c|c|c|c|}
\hline \multirow{2}{*}{\multicolumn{1}{|c|}{ Disease }} & \multicolumn{3}{|c|}{ Working period, years } \\
\cline { 2 - 5 } & $\begin{array}{c}\text { Short } \\
\text { er } \\
\text { than } \\
1 \\
\text { year }\end{array}$ & $1-2$ & $2-3$ & $\begin{array}{c}3 \\
\text { and } \\
\text { long } \\
\text { er }\end{array}$ \\
\hline ARVI & 40,8 & 32,6 & 22,3 & $\begin{array}{c}12,0 \\
2\end{array}$ \\
\hline Chronic bronchitis & 38,1 & 33,6 & 12,1 & 8,9 \\
\hline $\begin{array}{l}\text { Spinal column oste- } \\
\text { ochondrosis }\end{array}$ & 6,8 & 28,8 & 22,3 & 22,0 \\
\hline
\end{tabular}

Here we revealed some discrepancies in terms of extent to which adverse work influence became apparent. The first place belonged to female organs prolapse and ptosis due to hard physical labor mostly in standing position (EF was equal to $56.4 \%$ in female migrants in comparison with control group). 
Table 2

Risk of occupational pathology evolvement depending on working process hardness (\%)

\begin{tabular}{|l|c|c|c|c|c|}
\hline \multirow{2}{*}{ Type of mus-cle loads } & \multicolumn{5}{|c|}{ Working process hardness (as per P 2.2.755-99) } \\
\cline { 2 - 6 } & optimal & 1 class & 2 class, & \multicolumn{3}{|c|}{3 class, hazardous (hard labor) } \\
\cline { 4 - 6 } & acceptable & 1 degree & 2 degree & 3 degree \\
\hline Regional and basic & $0-6,0$ & $6,1-17,0$ & $17,1-28,0$ & $28,1-37,0$ & Более 37,0 \\
\hline
\end{tabular}

Table 3

Risk of occupational pathology evolvement (primary hypertension, ischemic heart disease and neurotic disorders) depending on labor intensity degree (\%)

\begin{tabular}{|l|c|c|c|c|c|}
\hline \multirow{2}{*}{ Pathologies } & \multicolumn{5}{|c|}{ Labor intensity degree } \\
\cline { 2 - 6 } & $\begin{array}{c}\text { I-low inten-sity } \\
(1)\end{array}$ & $\begin{array}{c}\text { II- average } \\
\text { intensity (2) }\end{array}$ & $\begin{array}{c}\text { III- high in- } \\
\text { tensity } \\
(3.1)\end{array}$ & $\begin{array}{c}\text { IV- very high } \\
\text { intensi-ty (3.2) }\end{array}$ & $\begin{array}{c}\text { V- exhaust-ing } \\
\text { intensity } \\
(3.3)\end{array}$ \\
\hline Primary hyper-tension & 0 & $0,1-10,3$ & $10,4-20,7$ & $20,8-29,1$ & $29,2-36,2$ \\
\hline Ischemic heart disease & 0 & $0,1-6,1$ & $6,2-21,2$ & $21,3-33,5$ & $33,6-43,8$ \\
\hline $\begin{array}{l}\text { Neurotic dis-orders (total } \\
\text { number) }\end{array}$ & 0 & $0,1-11.1$ & $11,2-24,2$ & $24,3-34,9$ & $35,0-43,9$ \\
\hline
\end{tabular}

Menstrual function disorders (EF was equal to $55.3 \%$ ) and inflammatory diseases of female pelvis organs (EF was equal to $45.7 \%$ in female migrants in comparison with control group) occupied the second place. Customary miscarriage and infertility took the third place.

Hard physical (muscle) labor causes greater risk of occupational diseases evolvement in musculoskeletal system and peripheral nervous system. We analyzed data of physiological and clinical examination performed on a great number of people and it allowed us to detect that occupational MSS and PNS diseases frequency in studied occupational groups depended on working process hardness (table 2).

Neuro-emotional labor intensity was considered to be a risk of production-induced diseases. Various disorders in cardiovascular system are known to evolve under apparent neuroemotional loads; such disorders include primary hypertension and ischemic heart disease. Mental stress at shift work and longer working period causes neurotic disorders evolvement. As per pro-duction research results we detected health risks depending on labor intensity degree (table 3).
High morbidity among labor migrants from Tajikistan leads to substantial economic losses. As we undergo transition period to market economy issues of preventive measures and therapy for them become really vital since migrants' health is a criterion of human factor efficiency in production process.

So, labor migrants' health is influenced by both external and internal risk factors such as climatic and ecological, social, and neuroemotional ones; these factors can cause various infec-tious and non-infectious diseases evolvement.

To preserve labor migrants' health and secure their high physical efficiency, we worked out medical and social support activities which form the 3rd subsystem in the whole system theory. Preventive activities are aimed at migrants' social provision, carrying out educational events, organizing professional selection and professional orientation, creating rational workrest regimes, performing treatment-anddiagnostics events, making supplements into legislative measures regulating labor migrants' work. 


\section{References}

1. Agadzhanyan N.A., Baevskiy P.M., Berseneva A.P. Uchenie o zdorov'e i problemy adaptacii [Health and adaptation problems' doctrine]. Stavropol', Stavropol'skij gosudarstvennyj universitet Publ., 2000, 204 p. (in Russian).

2. Anokhin P.K. Ocherki po fiziologii funkcional'nyh sistem [Essays on the physiology of functional systems]. Moscow, Nauka Publ., 1975, 447 p. (in Russian).

3. Baevskiy P.M. Prognozirovanie sostojanij na grani normy i patologii [Prediction of states on the verge of norm and pathology]. Moscow, Medicina Publ., 1979, 295 p. (in Russian).

4. Berseneva A.P. Principy i metody massovyh donozologicheskih obsledovanij s is-pol'zovaniem avtomatizirovannyh sistem: avtoref. dis. doktora biol. nauk [ Principles and methods of mass prenosological surveys using automated systems: Cand. Dis. Dr. biol. sciences]. Kiev, 1991, 28 p. (in Russian).

5. Budaev S.D. Mediko-social'nye aspekty ohrany zdorov'ja sel'skogo naselenija Respub-liki Burjatija: avtoreferat diss. kand. med. nauk [Medical and social aspects of the health of the rural population of the Republic of Buryatia: abstract of diss. of cand. of med. sciences]. Moscow, 1996, 22 p. (in Russian).

6. Baevskiy P.M., Ivanov G.G. [et al]. V pomoshh' prakticheskomu vrachu. Analiz variabel'-nosti serdechnogo ritma pri ispol'zovanii razlichnyh jelektrokardiograficheskih sis-tem: metodicheskie rekomendacii [To help the practitioner. The analysis of heart rate variability using different electrocardiographic systems: guidelines]. Vestnik aritmologii, 2001, no. 24, pp. 65-87 (in Russian).

7. Vremennye metodicheskie rekomendacii po raschetu pokazatelej professional'nogo riska [Interim guidelines for the calculation of professional risk indicators]. In N.F. Izmerov, ed. Moscow, Research Institute of Occupational Health, 2005, 16 p. (in Russian).

8. Matukhin V.V. Umstvennaja rabotosposobnost' s pozicii teorii o funkcional'-nyh sistemah (obzor literatury) [Concept of capacity for mental work treated by functional systems theory]. Medicina truda $i$ promyshlennaja jekologija, 1993, no. 3-4, pp. 28-31 (in Russian).

9. R 2.2.20006-05. Rukovodstvo po gigienicheskoj ocenki faktorov rabochey sredy i trudovogo processa. Kriterii i klassifikaciya usloviy truda [Guidance on the hygienic assessment of factors of working environment and labor process. The criteria and classification of working conditions]. Moscow, Federal'nyj centr gigieny i jepidemiologii Rospotrebnadzora, 2005, 142 p. (in Russian).

10. Bukhtiyarov I.V., Matukhin V.V., Jushkova O.I. [et al]. Fiziologicheskie osobennosti formirovanija psihojemocional'nogo perenaprjazhenija u rabotnikov umstvennogo truda i ego profilaktika [The physiological features of overstrain formation in mental work and its prevention]. Rossijskij fiziologicheskij zhurnal im. I.M. Sechenova, 2014, vol. 100, no. 11, pp. 1324-1334 (in Russian).

11. Akselrod S. Components of heart rate variability. Basic studies. In: Malik M., Inc., 1995, 147 p.

12. Allen J. The influence of physical conditions in the genesis of species. Ann. Rept. of the Smithsonian Institution. Washington, 1906, pp. 375-402.

13. Andersen K.L. Comparisons of Scandinavian Lapps, Arctic Fishermen, and Canadian Arctic Indians. Fed. Proc, 1963, vol. 22, pp. 834-839.

14. Canter D., Nanke L. Can health be a quantative criterion. A multifaceted approach to health assessment. Science of Health. Plenium Press, 1992, pp. 83-98.

15. Akselrod S., Gordon D., Madwed J.B. [et al]. Hemodynamic regulation: investigation by spectral analysis. Am. J. Physiol, 1985, vol. 249, pp. 867-875.

16. Akselrod S., Gordon D., Ubel F.A. [et al]. Power spectrum analysis of heart rate fluctuation: a quantitative probe of beat-to-beat cardiovascular control. Science, 1981, vol. 213, pp. 220-222.

Khodzhiev M., Prokopenko L.V., Golovkova N.P., Tikhonova G.I., Fesenko M.A. Adaptation of the migrant worker's body to the occupational risk factors from the position of functional system of P.K. Anokhin. Health Risk Analysis, 2016, no. 4, pp. 98-109. DOI: 10.21668/health.risk/2016.4.12.eng 
Received: 02.08.2016

Accepted: 05.12.2016

Published: 30.12.2016 